\title{
Determination of ELISA Reactive Mumps IgG Antibodies in MMR Vaccine Recipients in Comparison with MMR Vaccine Naive Children: a Cross Sectional Study
}

\author{
Riya Gupta, ${ }^{1}$ Naveen Saxena, ${ }^{1}$ Parul Gupta²
}

\begin{abstract}
Background/Aim: Mumps is by vaccine preventable infectious disease characterised by parotitis. In India mumps vaccines are not currently used under National Immunisation Programme (NIP). Waning of vaccine-induced immunity is considered to play a central role in the re-emergence of mumps. The comprehensive data on the seroepidemiology of measles, mumps, and rubella (MMR) as well as studies which compare the antibody titre among mumps vaccine naiveand mumps vaccinated children are lacking. The aim of this study was to estimate and compare mumps specific antibody titre in children with and without MMR vaccine.

Methods: In 2019/2020, blood samples were collected from 100 healthy children attending immunisation clinic in Government Medical College Kota and associated J K Lon Maternal and Child care hospital Kota. The samples were investigated for MMR IgG antibodies using ELISA.

Results: Out of total 100 children included in the study, $32.27 \%$ vaccinated and $4.83 \%$ non-vaccinated children were positive for mumps IgG antibody in the age group of 6 months to 6 years of age. Children aged 6 to 12 years, vaccinated and non-vaccinated, had $31.57 \%$ and $26.57 \%$ positivity, respectively. The seroprevalence of measles, mumps and rubella antibodies among 50 MMR vaccinated children were $94 \%, 64 \%$, and $96 \%$, respectively. A high measles and rubella seroprevalences were observed among all children age groups, suggesting an effective control program, while the mumps seroprevalence decreased significantly with age.

Conclusion: The maximum vaccine effectiveness against mumps for 2 doses of MMR vaccine is $\approx 96 \%$. The herd immunity threshold to block mumps virus transmission is $\geq 86 \%$. In this study only $64 \%$ of the vaccinated children were found to have IgG mumps antibodies. In view of morbidity following mumps infection there is a need to incorporate mumps vaccine along with measles and rubella vaccine in the NIP instead of MR.
\end{abstract}

Key words: Antibody; Measles; Mumps; Vaccination.
(1) Department of Microbiology, Government Medical College, Kota, Rajasthan, India.

(2) Department of Microbiology, SMS Medical College, Jaipur, Rajasthan, India.

Correspondence: RIYA GUPTA

E: riyagupta.rg215@gmail.com T: +918890004195

\section{Introduction}

Mumps is a contagious disease characterised by parotitis. Although perceived as a benign childhood disease, mumps was the leading cause of viral meningitis and encephalitis, as well as perma- nent deafness in children before the widespread vaccination. ${ }^{1}$ It is a vaccine-preventable disease that is endemic in most parts of the world. ${ }^{2}$ 
The burden of mumps remains high (100-1,000 cases/100,000 population) in countries that do not supply routine mumps vaccination, with epidemic peaks each 2-5 years. ${ }^{3,4}$ However, mumps disease outbreak have occurred even in countries using mumps vaccination in their National immunisation programs (NIPs)..$^{5-7}$ According to World Health Organisation (WHO), Southeast Asia Region (SEAR) reported 36,352 cases of mumps in $2013,^{8}$ however there is no information on the cases reported from India.

Mumps, despite being a widely prevalent disease everywhere in the country, is taken into account as associate degree insignificant public ill health in India, primarily due to poor documentation of clinical cases and lack of published studies. There is no across the nation representative knowledge on incidence of the illness. ${ }^{9}$

Although the illness is sometimes mild, its burden should not be underestimated. Up to $10 \%$ of mumps patients developed aseptic meningitis; a less common however more serious complication is encephalitis, which might end in death or disability; and permanent deafness, orchitis and pancreatitis are other untoward effects that may be prevented by vaccination. ${ }^{10}$ There is no specific treatment and vaccination is the solely effective way to forestall the disease. ${ }^{11}$

Measles is the most common cause of vaccine-preventable death in children and the eighth leading reason of death worldwide.

In India, measles-rubella vaccination was introduced in 2017. ${ }^{12}$ Measles cases in India have dropped considerably by banging $43 \%$ between 2015 and 2016 for the first time, as India builds on its acute anterior poliomyelitis obliteration campaign experience to eliminate measles by 2020 . By 2018, India planned to achieve 40 crore children with the measles vaccine, that is predicted to significantly scale back the illness burden and facilitate India meet its 2020 elimination target. ${ }^{13}$

Prior to introduction of vaccination program, rubella was endemic worldwide. Epidemics still occur in developing and tropical countries each four to seven years, however the lack of monitoring programs, along with the absence of severe clinical symptoms, has created them troublesome to assess. ${ }^{14}$

\section{Vaccination}

The mumps vaccine was first licensed in the US in 1967. Since the initiation of the mumps vaccine, reported cases of mumps have decreased by $99 \%$ from 185,691 cases in 1968 to only 906 cases in 1995. ${ }^{11}$

Mumps vaccination has been incorporated into the regular vaccination schedule of the many countries, usually with measles and rubella vaccines in triple formulation (MMR) ${ }^{15}$ at nine months, fifteen months, and four to six years of age, ${ }^{16}$ or as two doses at twelve to fifteen months with the second dose between four to six years of age. ${ }^{17}$ These vaccines have enabled the WHO to ascertain worldwide strategies for the advanced management of measles and rubella resulting in an elimination target in some regions. However, in contrast to rubella and measles, secondary vaccine failure happens oftentimes within the case of mumps and circulation of mumps virus inside highly immunised populations has been frequently reported. ${ }^{16}$

There are lower clinical attack rates among immunised populations; however, epidemics occur much within the second and third decade usually with severe complications. ${ }^{18}$ The monovalent measles vaccine is not offered for normal use. Measles-containing immunising agent (MMR/ MR) ought to be administered once at nine months of age under NIP of India.

Rubella vaccine is usually given together with measles and mumps as MMR vaccine between twelve and fifteen months of age, with a succeeding booster shot before school entry or in adolescence. ${ }^{19}$ Rubella vaccination ought to be given to all women of child bearing age found to possess low or undetectable antibody titre, preferably one month before conception or postnatal. Immunisation during pregnancy should be avoided because of risk of congenital rubella syndrome (CRS). ${ }^{21}$

Government of India has recently introduced some modifications within the NIP supporting the recommendation of National Technical Advisory Group on Immunization (NTAGI) where four new immunising agents were introduced ${ }^{22}$ and recommended conversion of MMR vaccine to MR vaccine (measles-rubella). As a result of it, it is felt that the disease burden of mumps is not very 
significant in India. Only a few studies are conducted to search out the seroprevalence of antibodies against mumps in Indian children. Indian Academy of Paediatrics (IAP), however, recommends the continuation of this vaccine since incidence of mumps remains high in Indian children.

\section{Aims and objectives}

Aim of this study was to compare mumps specific antibody titre in children vaccinated and not vaccinated with MMR vaccine. Primary objective was estimation of mumps specific IgG antibody in children, MMR naive and MMR vaccinated. Secondary objective was comparison of mumps specific IgG antibody level in above-mentioned children after quantitative estimation.

\section{Methods}

The study was conducted in the Department of Microbiology, Government Medical College, Kota and Department of Paediatrics of associated J K LON Maternal and Child Care Hospital, Kota, Rajasthan. This was a cross sectional observational study, for a period of 1 year (May 2019 - May 2020), in which 100 children between age group of six months to twelve years were investigated. They were divided into two groups. Fifty MMR vaccine naive and fifty MMR vaccinated children between six months to twelve years of age were included. Immunocompromised children, children presenting with acute febrile illness, children who have received blood products or immunoglobulins 3-11 months back, children above 12 years of age were not included in the study. IgG antibodies against measles, mumps, and rubella were measured in the serum by enzyme-linked immunosorbent assay (ELISA) using specific commercially available kits (DIESSE ENZYWELL, Italy). For each test run, control and standard sera were included independent of the number of micro-test strips used. The standard sera were set up in duplicate. All tests were performed and interpreted as per kit manufacturer's instructions.

The assay utilises the microtiter plate-based enzyme immunoassay technique by coating highly purified antibody onto the wall of microtiter well. The purified and inactivated mumps/ measles virus antigen was bound to the solid phase (8well strip). The specific immunoglobulins were bound to the antigen through incubation with diluted human serum. After washing, incubation was performed with the conjugate, composed of human IgG monoclonal antibodies labelled with peroxidase enzyme which was detected colourimetrically by adding an enzyme substrate. The optical density of the resulting dye complex was read spectrophotometrically at single wavelength of $450 \mathrm{~nm}$. The colour which was developed was proportional to the concentration of specific antibodies present in the serum sample. The average absorbance for each pair of duplicate test results was calculated.

The continuous data was described as mean and standard deviation, while discrete data was described as proportions. The association between qualitative variables was measured by Chi-squared test. The level of significance was considered at $5 \%(\alpha=0.05)$. The MATLAB 2016 and JASP 0.11.1.0 statistical package was used for statistical analysis.

\section{Results}

Among the 100 children included in the study mean age was 6.7 years ( $S D=3.7$ years) with male to female ratio of 57:43. Most of the children were from urban area (86\%) and literate families (85\%). Among all the children percentage of children vaccinated with MMR and MR vaccines were $50 \%$ and $78 \%$, respectively.

Out of 50 vaccinated children $68 \%(\mathrm{n}=34)$ were from 6 months to 6 years of age and $32 \%(n=16)$ were from 6 year to 12 years of age. While among non-vaccinated children $56 \%(\mathrm{n}=28)$ and $44 \%$ $(\mathrm{n}=22)$ were from 6 months to 6 years and 6 years to 12 years of age group, respectively (Table 1).

Table 1: Age distribution of MMR- vaccinated and non-vaccinated children

\begin{tabular}{lccc}
\hline \multirow{3}{*}{ MMR vaccination } & \multicolumn{2}{c}{ Age } & \\
\cline { 2 - 3 } & $\begin{array}{c}\text { 6 months } \\
-\mathbf{6} \text { years }\end{array}$ & $\begin{array}{c}\mathbf{6} \text { years } \\
\text {-12 years }\end{array}$ & Total \\
\hline Vaccinated & $34(68 \%)$ & $16(32 \%)$ & 50 \\
\hdashline Non-vaccinated & $28(56 \%)$ & $22(44 \%)$ & 50 \\
\hline Total & 62 & 38 & 100 \\
\hline
\end{tabular}

Age distribution showed significant association between MMR vaccination and antibody status in 
6 months to 6 years age group $\left(\chi^{2}=13.31 ; \mathrm{p}<\right.$ 0.001 ) but association in 6 year to 12 year age group $\left(\chi^{2}=3.81 ; p=0.05\right)$ was less significant.

In this study $62.96 \%(\mathrm{n}=17)$ males and $65.22 \%$ $(\mathrm{n}=15)$ females were positive for mumps IgG antibody among vaccinated children. While among non-vaccinated children only $30 \%(n=9)$ males and $20 \%(n=4)$ females were positive for IgG mumps antibody (Table 2).

Table 2: IgG mumps antibodies in MMR vaccinated and non-vaccinated children related to gender

\begin{tabular}{|c|c|c|c|c|c|c|}
\hline \multirow{2}{*}{$\begin{array}{l}\text { MMR } \\
\text { vaccination }\end{array}$} & \multicolumn{3}{|c|}{ Male } & \multicolumn{3}{|c|}{ Female } \\
\hline & Positive & Negative & Total & Positive & Negative & Total \\
\hline \multirow{2}{*}{ Vaccinated } & 17 & 10 & \multirow[b]{2}{*}{27} & 15 & 8 & \multirow[b]{2}{*}{23} \\
\hline & $(62.96 \%)$ & (37.04 \%) & & $(65.22 \%)$ & (34.78 \%) & \\
\hline Non-vaccinated & $\begin{array}{r}9 \\
(30 \%)\end{array}$ & $\begin{array}{r}21 \\
(70 \%)\end{array}$ & 30 & $\begin{array}{r}4 \\
(20 \%)\end{array}$ & $\begin{array}{r}16 \\
(80 \%)\end{array}$ & 20 \\
\hline Total & 26 & 31 & 57 & 19 & 24 & 43 \\
\hline
\end{tabular}

This data showed that there was significant association between MMR vaccination and mumps IgG antibody status ( $\left.\chi^{2}=14.59 ; \mathrm{p}<0.001\right)$.

There was $32.27 \%$ and $4.83 \%$ positivity in vaccinated and non-vaccinated children respectively in the age group of 6 months to 6 years. While in the age group from 6 years to 12 years there was $31.57 \%$ and $26.57 \%$ positivity, respectively. This data showed that there was significant association between MMR vaccination and antibody status in 6 months to 6 years age group $\left(\chi^{2}=13.31\right.$; $p<0.001)$ but in 6 years to 12 years age group $\left(\chi^{2}\right.$ $=3.81 ; \mathrm{p}=0.05$ ) was not significant as shown in Figure 1.

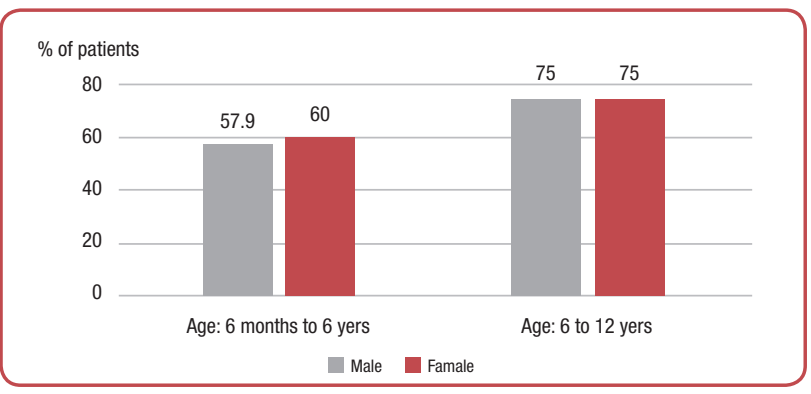

Figure 1: Age- and gender- wise distribution of positive IgG mumps antibodies among MMR vaccinated children

In MMR non-vaccinated children total positivity for IgG mumps antibody was $26 \%(\mathrm{n}=13)$ while $74 \%(n=37)$ were negative for all the age groups and gender. This data showed insignificant seropositivity among non-vaccinated group.
Out of 50 vaccinated children included in the study $100 \%(n=19)$ males and $93.33 \%(n=14)$ females were positive for measles IgG antibody in the age group of 6 months to 6 years. While among 6 to 12 year age group $100 \%(\mathrm{n}=8)$ males and $75 \%(n=6)$ females were positive for IgG measles antibodies. This data showed there was significant association between MMR vaccination and measles antibody status in all the age group irrespective of gender.

Out of 50 vaccinated children included in the study $89.47 \%(n=17)$ males and $80 \%(n=12)$ females were positive for rubella IgG antibody in the age group from 6 months to 6 years. While among 6 year to 12 year age group $100 \%(n=8)$ males and $75 \%(n=6)$ females were positive for IgG rubella antibodies showing significant association between MMR vaccination and rubella antibody status in all the age group irrespective of gender.

Total $78 \%$ children were MR vaccinated. Among 50 MMR vaccinated children $90 \%(\mathrm{n}=45)$ also received MR vaccination. While among non-vaccinated children only $66 \%(n=33)$ received MR vaccination as shown in Table 3.

Table 3: Percentage distribution of MR vaccination among MMR vaccinated and MMR non-vaccinated children

\begin{tabular}{lccc}
\hline MMR vaccination & MR vaccinated & MR non-vaccinated & Total \\
\hline Vaccinated & $45(90 \%)$ & $5(10 \%)$ & 50 \\
\hdashline Non-vaccinated & $33(66 \%)$ & $17(34 \%)$ & 50 \\
\hdashline Total & 78 & 22 & 100 \\
\hline
\end{tabular}

This represents that rate of MR vaccination is high in country to that of MMR vaccination. As in the current schedule of NIP, MMR vaccination is not recommended while private institutions give only MMR vaccines.

\section{Discussion}

The use of vaccine in developed countries successfully reduced mumps virus infection, though outbreaks are often reported. In developing countries, due to absence of effective vaccination due to various reasons such as illiteracy, poor reach to health care services, poor economy, mumps is still a major health issue. The burden of disease in India has still not been clearly defined because of very few studies over it. The present study rep- 
resents the current scenario of MMR vaccination in India.

As per WHO, MMR vaccine has been included in NIP of 121 countries. ${ }^{22}$ In India it is not a part of NIP. Recently measles and rubella elimination program has been launched by WHO in India which targets $95 \%$ coverage of measles immunisation in community with 2 doses of MR vaccine given, first dose at 9-12 months and second dose at 16-24 months of age. ${ }^{23}$ Mumps is not a part of this schedule as it is believed that mumps is a disease of moderate morbidity and mortality in Indian setup. ${ }^{9}$ Numerous studies both from India and other countries have reported many outbreaks of mumps in children and young adults both unvaccinated and vaccinated, ${ }^{24}$ mostly occurring in age group of 5-10 years. In a prospective study conducted at Finland, where mumps is almost eradicated, antibody titre of measles, mumps and rubella vanished within 20 years, but antibody titres of mumps decreased the most, suggesting poor immunogenicity of the vaccine. ${ }^{25}$

In the present study among the 100 children 50 $\%$ were MMR vaccinated and $50 \%$ were not. Out of 50 vaccinated children $68 \%(n=34)$ were from 6 months to 6 years of age and $32 \%(n=16)$ were from 6 to 12 years of age. While among non-vaccinated children $56 \%(\mathrm{n}=28)$ and $44 \%$ $(\mathrm{n}=22)$ were from 6 months to 6 years and 6 years to 12 years age group, respectively. Similarly, in a study done by Wang et al, ${ }^{26}$ where 42.25 $\%$ children were younger than 6 years of age and $57.75 \%$ were from 6-12-year age group. In contrast to a prospective study done by Rout et al, ${ }^{27}$ where $33.33 \%$ of children included in the study were younger than 6 years in compare to $61.11 \%$ from 6-12-year age group.

Sixty-four percentage $(n=32)$ of the 50 vaccinated children had IgG mumps antibodies. Out of these, $62.5 \%(n=20)$ belong to age group from 6 months to 6 years. This denotes that antibody response declines with increasing age and booster vaccination is required to maintain immunity against mumps. Also it can be due to low seroconversion rate of mumps antibody leading to low immunity. Exact time of vaccination cannot be estimated in India as in India most people belong to rural population and does not maintain records. For prevention of a disease outbreak of mumps at least $90 \%$ of vaccine coverage of the population should be present to maintain and ef- fective herd immunity as supported by previous studies. ${ }^{28}$ In this study only $64 \%$ of vaccinated population had immunity against mumps which is inadequate to prevent an outbreak. Similarly, in a study done by Wang et $\mathrm{al}^{26}$ among all positive children $70.39 \%$ belong to younger than 6 years age group for IgG mumps antibodies. In contrast, in study done by Adam et $\mathrm{al}^{29} 63.6 \%$ of children were positive for IgG mumps antibody, $34.01 \%$ of them belong to younger than 6 years age group and $65.99 \%$ belong to older than 6 years age group. In their study the mumps and rubella seroprevalence increased significantly with age documenting active wild type circulation.

Among the 50 non-vaccinated children, $26 \%$ ( $\mathrm{n}=$ 13) of children had presence of IgG mumps antibodies. It was seen that children aged 6-12 years had higher IgG mumps seroconversion as compared to younger children. This could be possibly due to prior exposure to a case of mumps or boosting of natural immunity with age. These results may be an overstatement of the current scenario within the community since the study was conducted on a limited number of participants due to various constraints; also the distribution of participants according to their age and gender was not uniform in each age group. Also it can be due to more chances of accounting an infection in later ages so mumps vaccination is necessary for these children.

Studies from other countries where two doses of MMR vaccination are recommended have reported seroconversion rate of 63-95 \% after second dose. $^{30}$ Low seroconversion rate were also expected in communities reporting mumps outbreaks.

Among the 50 MMR vaccinated children $94 \%$ ( $=$ 47) were positive for IgG measles antibodies. This shows high seroconversion rate of measles among the vaccinated individuals. Similarly, in study done by Adam et $\mathrm{al}^{29}$ and Wang et $\mathrm{al}^{26}{ }^{26}$ among the MMR vaccinated children $93.5 \%$ and $95 \%$ were positive for IgG measles antibodies, respectively.

In the present study $96 \%(n=48)$ out of 50 MMR vaccinated children were positive for IgG rubella antibody, $60.42 \%(n=29)$ of which are from 6 months to 6 years of age while rest, $39.58 \%$ (n = 11) were older than 6 years of age. Similarly, in a study done by Poethko-Muller et $\mathrm{al}^{31} 75 \%$ were from 6 months to 6 years of age. In contrast a 
study done by Adam et al ${ }^{29}$ only $17 \%$ were from 6 months to 6 years of age. This data showed that the seroconversion for rubella is also high among MMR vaccinated children.

Out of 50 MMR vaccinated children only $64 \%$ have IgG mumps antibodies in compare to $94 \%$ IgG measles and $96 \%$ IgG positivity of rubella. Overall, mumps seroconversion is poor due to one dose of vaccine, so another booster of MMR is required to complete coverage of mumps and prevent infection.

In present study, $78 \%$ of all children were MR vaccinated. Among 50 MMR vaccinated children $90 \%(\mathrm{n}=45)$ also received MR vaccination. Among non-vaccinated children only $66 \%$ ( $\mathrm{n}=$ 33) received MR vaccination. This showed that rate of MR vaccination is high in country due to MMR vaccination, as MR vaccine is currently not available in the private sector in India. In view of morbidity following mumps infection, it has been recommended by IAP that MMR is administered instead of MR. Irrespective of previous vaccination status, additional dose of MR vaccine during MR campaign for children 9 months to 15 years, is to be administered, keeping in mind the need to support national programs. ${ }^{32}$

In view of these results the decision of Government of India and NTAGI on replacing MMR with MR vaccine may require reconsideration since mumps rivals - measles and rubella in its ability to cause outbreak and possible congenital malformations in children. Removing mumps vaccine from states with $<70 \%$ of MMR vaccine coverage can also lead to potential outbreak in future once MR vaccine completely replaces MMR vaccine.

The results of this study were in concordance with previous reports that a single dose is not sufficient to prevent clinical mumps and natural immunity in Indian children and it is not sufficient enough to offer protection upon exposure to the agent. Also, poor efficacy in vaccinated children causes a rightward shift in the epidemiology and affects older children and young adults. This widens the clinical severity of disease. Blanket withdrawal of mumps component of MMR cannot be a final decision without a strong backup of long-term epidemiological data.

\section{Conclusion}

The maximum vaccine effectiveness against mumps for 2 doses of MMR vaccine is $\approx 96 \%$. The herd immunity threshold to block mumps virus transmission is $\geq 86 \%$. In present study, only $64 \%$ of the vaccinated children were found to have IgG mumps antibodies. This concludes firstly low seroconversion rate of mumps antibody leading to low immunity and secondly, the antibody response declines with increasing age and booster vaccination is required to maintain immunity against mumps. High seroconversion rate of measles and rubella among vaccinated group was found. Hence in view of morbidity following mumps infection, the results highlight the need to incorporate mumps vaccine along with measles and rubella vaccine in the NIP instead of MR. Irrespective of previous vaccination status, additional dose of MR vaccine during MR campaign for children 9 months to 15 years, is to be administered, keeping in mind the need to support national programs. By preventing measles, rubella and mumps together, significant savings for our country and communities could be provided.

\section{Acknowledgements}

None.

\section{Conflict of interest}

None.

\section{References}

1. Plotkin SA, Rubin SA. Mumps vaccines. Chapter 40. In: Plotkin SA, Orenstein WA, ed. Vaccines. 7th ed. Philadelpia: Elsevier; 2018.

2. Hatchette TF, Mahony JB, Chong S, LeBlanc JJ. Difficulty with mumps diagnosis: What is the contribution of mumps mimickers? J ClinVirol 2009;46:381-3.

3. World Health Organization. Position paper. Mumps virus vaccines. Wkly Epidemiol Rec 2007;7:51-60.

4. Galazka AM, Robertson SE, Kraigher A. Mumps and mumps vaccine: a global review. Bull World Health Organ 1999;77(1):3-14. 
5. Atrasheuskaya AV, Kulak MV, Rubin S, Ignatyev GM. Mumps vaccine investigation in Novosibirsk, Russia, 2002-2004. Clin Microbiol Infect 2007;13:670-6.

6. Centers for Disease Control and Prevention (CDC). Update: mumps outbreak - New York and New Jersey, June 2009-January 2010. MMWR Morb Mortal Wkly Rep 2010 Feb 12;59(5):125-9.

7. Kutty PK, McLean HQ, Lawler J, Schulte C, Hudson JM, Blog $\mathrm{D}$, et al. Risk factors for transmission of mumps in a highly vaccinated population in Orange County, NY, 2009-2010. Pediatr Infect Dis J 2014;33:121-5.

8. World Health Organization. Global and Regional Immunization Profile; South-East Asia Region [Internet]. [Cited: 3 Jan 2020]. Available from: http:/ /www. who.int/immunization/monitoring_surveillance/data/gs_seaprofile.pdf.

9. Vashishtha VM, Yadav S, Dabas A, Bansal CP, Agarwal RC, Yewale VN, et al. IAP Position Paper on burden of mumps in India and vaccination strategies. Indian Pediatr 2015;52:505-14.

10. Galazka AM, Robertson SE, Kraigher A. Mumps and mumps vaccine: a global review. Bull World Health Organ 1999;77(1):3-14.

11. Carlton R. The Association between the measles, mumps, and rubella vaccine and the development of autism: a meta-analysis [dissertation]. University of South Florida, USA; 2008.

12. Giammanco G, Li Volti S, Salemi I, Giammanco Bilancia G, Mauro L. Immune response to simultaneous administration of a combined measles, mumps and rubella vaccine with booster doses of diphtheria-tetanus and poliovirus vaccine. Eur J Epidemiol 1993 Mar;9(2):199-202.

13. Sushmi D. Measles cases in India dropped by $43 \%$ in a year: WHO. [Internet]. [Cited: 3 Jan 2021]. Available from: https://timesofindia.indiatimes.com/life-style/ health-fitness/health-news/measles-cases-in-indiadropped-by-43-in-a-year-who/articleshow/60476283. cms.

14. Robertson SE, Cutts FT, Samuel R, Diaz-Ortega JL. Control of rubella and congenital rubella syndrome (CRS) in developing countries, Part 2: Vaccination against rubella. Bull World Health Organ 1997;75:69-80.

15. Echevarria JE, Castellanos A, Sanz JC, Perez C, Palacios G, Martinez de, et al. Circulation of mumps virus genotypes in Spain from 1996 to 2007. J ClinMicrobiol 2010;48:124554.

16. Vashishtha VM, Yewale VN, Bansal CP, Mehta PJ. Indian Academy of Pediatrics, Advisory Committee on Vaccines and Immunization Practices (ACVIP). IAP perspectives on measles and rubella elimination strategies. Indian Pediatr 2014;51:719-22.

17. Centers for Disease Control and Prevention (CDC). Measles, mumps, and rubella (MMR) vaccination: what everyone should know [Internet]. [Cited: 18 Nov 2018]. Available from: https:// www.cdc.gov/vaccines/vpd/mmr/ public/index.html.

18. Mithra PP, Unnikrishnan B, Rekha T, Kumar N, Chatterjee PK, Holla R. Immunization practices of pediatricians for children younger than five years in coastal South India. J Prim Care Community Health 2015 Apr;6(2):116-20.

19. O'Shea S, Woodward S, Best JM, Banatvala JE, Holzel H, Dudgeon JA. Rubella vaccination: persistence of antibodies for 10-21 years. Lancet 1988 Oct 15;2(8616):909. doi: 10.1016/s0140-6736(88)92512-3.
20. O'Shea S, Best JM, Banatvala JE. Viremia, virus excretion, and antibody responses after challenge in volunteers with low levels of antibody to rubella virus. J Infect Dis 1983 Oct;148(4):639-47.

21. National Technical Advisory Group on Immunization (NTAGI), 16 June $2008 \mathrm{E}$. Introduction of MMR/MR vaccine. p. 2-3. [Internet]. [Cited: 18 Nov 2018]. Available from: https://main.mohfw.gov.in/sites/default/ files/8706936084National\%20Technical\%20Advisory $\% 20$ Group $\% 20$ on $\% 20$ Immunization $\% 20 \% 28$ NTAGI\%29\%20minutes\%20of\%20meeting\%20NEW.pdf

22. World Health Organisation. Immunization coverage, 2018. [Internet]. [Cited: 3 Apr 2018]. Available from: http:// www. who. int/mediacenter/factsheets/fs378/en/\#.

23. Vashishtha VM, Yewale V, Bansal CP, Mehta PJ. IAP perspectives on measles and rubella elimination strategies. Indian Pediatrc 2014;51:719-21.

24. Hukic M, Hajdarpasic A, Ravlija J, Ler Z, Baljic R, DedeicLjubovic A, et al. Mumps outbreak in the Federation of Bosnia and Herzegovina with large cohorts of susceptibles and genetically diverse strains of genotype G, Bosnia and Herzegovina, December 2010 to September 2012. Euro Surveill 2014;19(33):1-8.

25. Davidkin I, Jokinen S, Broman M, Leinikki P, Peltola H. Persistence of measles, mumps, and rubella antibodies in an MMR-vaccinated cohort: a 20-year follow-up. J Infect Dis 2008 Apr 1;197(7):950-6.

26. Wang Z, Yan R, He H, Li Q, Chen G, Yang S, et al. Difficulties in eliminating measles and controlling rubella and mumps: a cross-sectional study of a first measles and rubella vaccination and a second measles, mumps, and rubella vaccination. PLoS One 2014 Feb 20;9(2):e89361. doi: 10.1371/journal.pone.0089361.

27. Raut CG, Sinha DP, Jayaprakash H, Hanumiah H, Manjunatha MJ. Mumps disease outbreak in Davangere district of Karnataka, India. Indian J Med Microbiol 2015 JulSep;33(3):378-82.

28. World Health Organisation (WHO). Measles and Rubella initiative: Annual report, 2013. [Internet]. [Cited: 3 Apr 2018]. Available from: http://www.who.int/immunization/diseases/measles/mri_annualreport_2013.pdf.

29. Adam O, Musa A, Kamer A, Sausy A, Tisserand E, Hübschen JM. Seroprevalence of measles, mumps, and rubella and genetic characterization of mumps virus in Khartoum, Sudan. Int J Infect Dis 2020 Feb;91:87-93.

30. WHO position paper. Mumps virus vaccines. Wkly Epidemiol Rec 2007 Feb 16;82(7):51-60.

31. Poethko-Müller C, Mankertz A. Seroprevalence of measles-, mumps- and rubella-specific IgG antibodies in German children and adolescents and predictors for seronegativity. PLoS One 2012;7(8):e42867. doi: 10.1371/journal. pone.0042867.

32. Balasubramanian S, Shah A, Pemde HK, Chatterjee P, Shivananda S, Guduru VK, et al; IAP Advisory Committee on Vaccines and Immunization Practices, 2018-19. Indian Academy of Pediatrics (IAP) Advisory Committee on Vaccines and Immunization Practices (ACVIP) recommended immunization schedule (2018-19) and update on immunization for children aged 0 through 18 years. Indian Pediatr 2018 Dec 15;55(12):1066-74. 